the reader, without specialist knowledge, to distinguish between the hunting techniques for which there is archaeological evidence, and those which are surmised. Many archaeological readers will be intrigued by the theory (pages 72-73) that Acheulean S-twist handaxes have "exactly the 'twist' characteristic of the boomerang, though without the aerofoil section which gives the latter lift when rapidly rotating in the air. It is conceivable that the 'twisted ovate' had some similar purpose, for it is hard to see any reason for the shape in a mere hand tool ... if frequently thrown about in stony surroundings by their users one would expect to find evidence of a good many breakages, in view of the brittleness of hard stones. Broken 'twisters' are not specially common."

Because the general reader has been so sheltered from technicalities in the first four chapters, it comes as a surprise to find him submitted to a barrage of Latin names for a vast range of species in the second half of the book. In discussing the invertebrates (page 105) we learn that "Whole phyla (primary subdivisions of the Animal Kingdom) are unrepresented on land. Even of those which are present, few individuals are large enough and numerous enough in one place to be worth searching for or collecting as food. Some exceptions are perhaps:

"Worms - the larger earthworms (Lumbricus spp.).

"Molluses - a few species of the larger snails (e.g., Helix, Cepaea) and possibly slugs (e.g., Arion, Limax), with several species of freshwater mussels (Unio spp.).

"Crustacea-freshwater crayfish (Astacus). The terrestrial species such as woodlice (Oniscus) are too small to notice."

From this, it is impossible to gather whether or not these species formed a significant part of the diet of our palaeolithic ancestors, or to assess their significance in the animal environment of early man. As one reaches the end of the volume, one becomes aware of a suspicion that the author has changed the aim of his book, and this is reflected in the final sentence of the conclusion in which an appeal is made to the readers to take a practical hand in systematic field and museum study of fossil mammals.

JANE M. RENFREW

\section{MATTERS FOR ARGUMENT}

\section{Bird Navigation}

By G. V. T. Matthews. Second edition. (Cambridge Monographs in Experimental Biology, No. 3.) (Cambridge University Press: London, September 1968.) $40 \mathrm{~s} ; \quad \$ 7$.

BIRD navigation is an old mystery and this new edition of Dr Matthews's book shows that it is no less so today. Much has happened in this field since the first edition was published thirteen years ago; there are 350 references from this period against 220 pre-1954 papers. The subject remains one on which direct experiment is, in the main, impossible; experiments have to be performed which deal indirectly with the central problem of the sensory behaviour of the flying bird. Inferences from these experiments enable theories to be erected, but as yet these are mostly untestable.

Now discoveries made by Matthews after the first publication of this book have enabled the author to confound some of his critics and to reinterpret some of the apparently anomalous results. This is one of those untidy parts of biology carpeted with loose ends. The work on "nonsense navigation" described very fully in this book has served to tie some of the ends into the carpet's pattern; the subject is becoming neater even if it is no more explicable.

Theories there must be, however, and if they cannot be tested by experiment then the likelihood of their being right must be tested by argument. Matthews has been responsible for a major theory of how birds use the Sun for navigation from a previously unknown place. In the light of the evidence he presents, it is difficult to deny that the Sun is a major source of stimuli by which the bird guides its flight. It is the bird's selection of the various measurements which can be made of the Sun's path and position, related to time, and the processing of this information within the central nervous system which is the matter for argument. The proved ability of birds to obtain their direction by means of some aspect of the stars is even more difficult to explain.

The field covered by the book is much the same as in the first edition, but new material raises the level of explanation; there are fifty more pages, but in addition a great deal of condensation of the earlier work has been done. It remains a lucid, succinct (if at times laconic), closely reasoned statement of the present position of work on this very difficult subject. J. D. CARTHy

\section{COMPARATIVE ZOOLOGY}

\section{Lower Animals}

By Martin Wells. (World University- Press.) Pp. 256. (Weidenfeld and Nicolson: London, 1968.) $18 s$.

Is the space of about fifty thousand words, this book provides a comparative account of all the major invertebrate taxa with the exception of the protozoa. Particularly close attention is given to those molluses such as the octopus, cuttlefish and squid, which have served as the author's research material. Martin Wells writes clearly-emphasizing the importance of behaviour in the survival of both the individual and the species, and providing a comparative discussion of sensory structure and function, and the organization of nervous tissue (including memory and associative learning).

Beginning with the sponges at the lowest level of organization and working through to the insects and the cophalopods, he describes the increases in complexity characteristic of the different animal forms. Also very well described are the dynamies and limitations of various types of locomotion and the importance of hormonal regulatory systems.

The author is careful to point out that the success of an organism is not to be measured only in terms of the degree of complexity of the nervous system, and he emphasizes this argument in a discussion on sessile and parasitic modes of life. Neither is the book concerned only with behaviour, for aspects of anatomy, ecology, reproductive physiology, population dynamics, the effects of natural selection, and some tentative evolutionary relationships are all discussed.

The style is refreshingly light, verging on comedy in the case of the section on parasitism, and difficult points are put simply without appearing trite or dogmatic. The illustrations are well arranged and annotated by Audrey Besterman and Mary Waldron, but they sometimes suffer from being printed in three tones-orange, grey and black-and in pursuit of clarity they have occasionally erred towards becoming too diagrammatic.

The introduction claims that the work is intended for both lay and professional readers, and that: "a gentleman should know something of invertebrate zoology, as a matter of general education". While it is pleasant to think that agreement with this ideal is widespread, some gentlemen in pursuit of it might find this particular example a little difficult without some prior knowledge, in spite of the concise invertebrate classification in the appendix.

This book will be most useful to students new to university. Its readability and low price commend it to anyone who knows something about invertebrate zoology and who wishes to understand the approach of the zoologist.
John A. PatTerson 